\title{
Article
}

\section{Formulation and development of orodispersible sustained release tablet of domperidone}

Patil, Hemlata, Tiwari, Roshan, Repka, Michael A and Singh, Kamalinder $\mathrm{K}$

Available at http://clok.uclan.ac.uk/14568/

Patil, Hemlata, Tiwari, Roshan, Repka, Michael A and Singh, Kamalinder K ORCID: 0000-0001-7325-0711 (2016) Formulation and development of orodispersible sustained release tablet of domperidone. Drug Development and Industrial Pharmacy, 42 (6). pp. 906-915. ISSN 0363-9045

It is advisable to refer to the publisher's version if you intend to cite from the work. http://dx.doi.org/10.3109/03639045.2015

For more information about UCLan's research in this area go to http://www.uclan.ac.uk/researchgroups/ and search for <name of research Group>.

For information about Research generally at UCLan please go to http://www.uclan.ac.uk/research/

All outputs in CLoK are protected by Intellectual Property Rights law, including Copyright law. Copyright, IPR and Moral Rights for the works on this site are retained by the individual authors and/or other copyright owners. Terms and conditions for use of this material are defined in the policies page.

\section{CLoK}

Central Lancashire online Knowledge www.clok.uclan.ac.uk

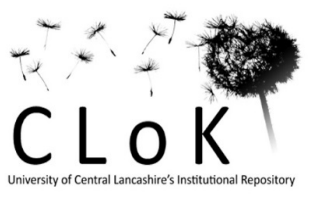


Formulation and Development of Orodispersible Sustained Release Tablet of Domperidone

Authors

Hemlata G. Patil ${ }^{1}$, Roshan Tiwari ${ }^{2}$, Michael A Repka ${ }^{2}$ and Kamalinder K. Singh ${ }^{1,3 *}$

Address

${ }^{1}$ C.U.Shah College of Pharmacy, SNDT Women's University, Mumbai 400049, India.

${ }^{2}$ Department of Pharmaceutics \& Drug Delivery, University of Mississippi, Mississippi 38677, USA

${ }^{3}$ School of Pharmacy and Biomedical Sciences, University of Central Lancashire, Preston, PR1 2HE, UK

*Corresponding author; Tel. No.: +441772895843

e-mail: ksingh1@uclan.ac.uk

Key words : Antiemetic, melt-in-mouth, microspheres, ethyl cellulose 


\title{
Formulation and Development of Orodispersible Sustained Release Tablet of Domperidone
}

\begin{abstract}
Commercially available domperidone orodispersible tablets (ODT) are intended for immediate release of the drug but none of them have been formulated for sustained action. The aim of the present research work was to develop and evaluate orodispersible sustained release tablet (ODT-SR) of domperidone, which has the convenience of ODT and benefits of controlled release product combined in one. The technology comprised of developing sustained release microspheres (MS) of domperidone, followed by direct compression of MS along with suitable excipients to yield ODT-SR which rapidly disperses within 30 seconds and yet the dispersed MS maintain their integrity to have a sustained drug release. The particle size of the MS was optimized to be less than $200 \mu \mathrm{m}$ to avoid the grittiness in the mouth. The DSC thermograms of MS showed the absence of drug-polymer interaction within the microparticles, while SEM confirmed their spherical shape and porous nature. Angle of repose, compressibility and Hausner's ratio of the

blend for compression showed good flowability and high percent compressibility. The optimised ODT-SR showed disintegration time of 21 seconds and matrix controlled drug release for $9 \mathrm{~h}$. Invivo pharmacokinetic studies in Wistar rats showed that the ODT-SR had a prolonged MRT of $11.16 \mathrm{~h}$ as compared $3.86 \mathrm{~h}$ of conventional tablet. The developed technology is easily scalable and holds potential for commercial exploitation.
\end{abstract}

Keywords: Antiemetic, orodispersible tablet, microspheres, sustained release. 


\section{Introduction}

Oral tablets have been the most popular and successfully used dosage form for delivery of drugs because of the convenience for use, ease of administration, simplicity in production and low cost of such systems. However, problems may arise in the administration of tablets to patients who have difficulty in swallowing, for example children, elderly people or more seriously ill patients. Orodispersible tablet (ODT) is good for such subpopulations, in general for paediatric and geriatric patients $^{1}$ or patients with swallowing dysfunction or dysphagia ${ }^{2}$. ODTs disintegrate in the oral cavity within seconds and are washed out with saliva without the need of liquid ${ }^{3}$. These tablets are also suitable for those who are travelling and do not have easy access to water, mentally ill, bedridden and patients with persistent nausea ${ }^{4-6}$. It is also useful for the patients, where the underlying disease disrupts swallowing ability (e.g. migraine, Parkinson's disease $)^{7-9}$. Studies have shown distinct patient preference for ODTs over regular tablets in certain disease conditions ${ }^{10-12}$.

ODTs by virtue of their fast disintegration are meant for immediate release of drug. Though these tablets cater to patients with swallowing difficulties and other patient needs as outlined above however, they are required to be administered frequently, depending upon the biological half-life of the drug and may lead to poor patient compliance. This limitation can be overcome by designing sustained release (SR) or controlled release drug delivery system ${ }^{13-15}$. The current sustained release technologies can be exploited and incorporated into an ODT to improve their functionality reducing need of multiple dosing regimens, improving patient adhereance, provide predictable and reproducible drug release, maintain steady drug plasma levels and reduce dose-dependent side effects associated with the repeated administration ${ }^{16}$. 
Domperidone (5-chloro-1-[1-[3-(2-oxo-2,3-dihydro-1H-benzimidazol-1-yl)propyl]piperidine-4yl]-1,3-dihydro-2H-benzimidazol-2-one; (Figure 1), is a weak base ( $\mathrm{pKa}=7.89$ ), practically insoluble in water and with a lipid to water ratio $(\log \mathrm{P})$ of $3.90^{17}$. It is a potent drug exerting its gastrokinetic action by acting on the peripheral dopamine.sub. 2 receptors in the GIT and is a unique compound with both gastrokinetic and antiemetic activity ${ }^{18,19}$. Unlike metoclopramide, another dopamine-receptor antagonist, domperidone does not readily cross the blood-brain barrier; therefore it has rather minimal extrapyramidal side effects. Clinically, domperidone has been shown to be useful in the treatment of various gastric motility disorders, namely chronic and subacute gastritis, to prevent GI symptoms associated with the use of dopamine agonists in Parkinson's disease, in diabetic gastroparesis, in anorexia nervosa and in patients with postvagotomy gastroparesis ${ }^{20}$. Commercially available orodispersible domperidone tablets are meant for immediate release of the drug and are given 3-4 times a day due to the short half-life $(\sim 7 \mathrm{~h})$.

One of the approaches to prepare controlled release formulations is the use of microsphere (MS) or microparticles of drug-polymer composites, where the active ingredient is distributed in the polymer matrix ${ }^{21,22}$. The polymeric matrix allows for slow, controlled and predictable drug release over a period of time and hence reduces the overall amount of drug needed to be incorporated ${ }^{23,24}$. The present work reports development of orodispersible sustained release tablets (ODT-SR) of domperidone which includes, first the preparation of sustained release MS of domperidone which were then compressed along with suitable excipients to give orodispersible sustained release tablet with the desired characteristics. This tablet is intended to disintegrate rapidly within the mouth into microspheres which will deliver the drug in a sustained manner after swallowing. For better 
patient-compliance, after disintegration of the tablet in the mouth, the disintegrated material should be small in particle size, so that patients do not feel the unpleasant grittiness of bigger particles. The maximum particle size with which patients do not feel the sandy feeling or rough sensation on the tongue is around $200 \mu \mathrm{m}$, so the particle size of MS was envisaged to be less than $200 \mu \mathrm{m}$ to avoid any rough mouth feel ${ }^{25}$. Such a formulation would have all the advantages and convenience of ODT dosage form and would simultaneously provide sustained release of the drug.

Furthermore, although orodispersible tablet with sustained release properties is reported ${ }^{26-29}$ incorporating MS prepared by emulsion solvent evaporation technique into ODT has not been investigated. MS of domperidone are very easy to prepare by this emulsion solvent evaporation technique and can be beneficial commercially.

\section{Materials and Methods}

\section{Materials}

Domperidone was obtained as a gift sample from Ipca laboratories Ltd, Mumbai. Avicel (FMC Biopolymer), Pearlitol 200 SD (Roquette), lactose, Polyplasdone XL-10, sodium saccharine, magnesium stearate (Ferro), Aerosil 200 were received as gift samples from Signet Chemicals, Mumbai. Ethocel Std. 10 was a gift sample from Dow, India. Directly compressible microcrystalline cellulose (Avicel PH- 102, particle size $\sim 100 \mu \mathrm{m}$ ) was gift from FMC Biopolymers, India. Ethanol, Span 80, liquid paraffin and n-hexane were purchased from S.D.

Fine chemicals, Mumbai. Domilon-MD ${ }^{\circledR}$ (Senate Labs) and Domperi- $10^{\circledR}$ (Saorite Phamracetuicals) were purchased from a local pharmacy in Mumbai.

\section{Methods}

Formulation of ODT-SR 
Formulation of ODT-SR involved two steps:

a) Preparation and characterization of sustained release MS of domperidone

b) Preparation of ODT-SR incorpoarating domperidone MS

\section{Preparation of Sustained Release microspheres}

MS of domperidone were prepared by emulsion solvent evaporation method ${ }^{30,31}$. Formulations were prepared by varying drug: polymer ratios. Drug and polymer were dissolved in ethanol. The above mixture was added dropwise with help of syringe in light liquid paraffin and stirred at 2000 rpm for four hours. The formed MS were vacuum filtered and then freed from liquid paraffin by repeated (2-3 times) washing with n-hexane and further the product was air dried over a period of $12 \mathrm{~h}$ to remove completely the traces of $\mathrm{n}$-hexane and sieved through US sieve no. 70. Optimization studies were conducted to investigate the effect of formulation variables on characteristics of domperidone MS. A randomized $3^{2}$ full factorial design was used to optimize the effect of two input variables i.e. polymer concentration $\left(\mathrm{X}_{1}\right)$ and drug concentration $\left(\mathrm{X}_{2}\right)$ in the $\mathrm{MS}$ on three response variables i.e. mean particle size, percent yield and percent drug entrapment (Table 1a).

\section{Characterisation of Domperidone Microspheres}

\section{a) Particle Size}

Particle size of the MS were characterized using optical microscopy (Olympus microscope, India). Measurement of 200 microspheres was taken and mean particle size and particle size distribution were determined ${ }^{32}$.

\section{b) Calibration Curve of the Domperidone}

As domperidone is poorly soluble in water, organic solvent is required to solubilize the drug. Therefore, stock solution of domperidone was prepared in methanol and working standards were prepared by suitably diluting with $0.1 \mathrm{M} \mathrm{HCl}$ and the absorbance were measured using UV-Vis 
Spectrophotometer (Jasco, MD, USA) at $\lambda \max 287 \mathrm{~nm}$ against blank. Calibration curve was plotted between drug concentration $(2-20 \mu \mathrm{g} / \mathrm{ml})$ and absorbance for each of the working standards.

\section{c) Drug Entrapment Efficiency}

A weighed quantity of MS were crushed into powder and added to $100 \mathrm{ml}$ of $0.1 \mathrm{M}$ Hydrochloric acid $(\mathrm{HCl})$. The resulting mixture was kept stirring at $1000 \mathrm{rpm}$ for $2 \mathrm{~h}$. Then the solution was filtered through membrane filter of $0.45 \mu \mathrm{m}$ pore size and $1 \mathrm{ml}$ of this solution was diluted using $0.1 \mathrm{M} \mathrm{HCl}$ and analyzed for domperidone content using UV Spectrophotometer at $\lambda \max$ of 287 nm. The drug entrapment efficiency was calculated using the following equation:

$$
\text { Drug entrapment efficiency }=\frac{\text { Experimental drug content }}{\text { Theoretical drug content }} \times 100
$$

\section{d) Percent Yield}

The prepared MS were collected and weighed. The weight obtained was divided by the total amount of all non-volatile components which were used for the preparation of the MS.

$$
\% \text { Yield }=\frac{\text { Actual weight of product }}{\text { Total weight of excipients and drug }} \times 100
$$

\section{e) Scanning Electron Microscopy (SEM)}

The surface characteristics of drug loaded MS were examined by means of a scanning electron microscopy. The MS were coated with gold or palladium under vacuum using a sputter coater and then samples were examined under the scanning electron microscope (Philips XL 30 SEM) setup at $10 \mathrm{kv}$ with a till of $45^{\circ}$. Using suitable magnification SEM micrographs of domperidone loaded MS were recorded. 


\section{f) Differential Scanning Calorimetry (DSC)}

Drug-polymer interactions were studied by DSC (Q 2000 TA Instruments) analysis. The DSC analysis of pure domperidone, ethyl cellulose and domperidone MS was carried out by heating samples in the range of 30 to $340{ }^{\circ} \mathrm{C}$ at a rate of $10{ }^{\circ} \mathrm{C} \mathrm{min}{ }^{-1}$ and the thermograms were recorded.

\section{g) In-vitro Drug release}

$100 \mathrm{mg}$ of drug loaded MS were tied in nylon cloth and kept in the basket which was then immersed in the dissolution medium $(0.1 \mathrm{M} \mathrm{HCl}, 900 \mathrm{ml})$ and stirred at $100 \mathrm{rpm}$ using USP dissolution Apparatus II (Electrolab EDT-08Lx). $5 \mathrm{ml}$ of aliquots of medium were removed after $30 \mathrm{~min}, 1$, $2,3,4,5,6,7,8,9$, and $10 \mathrm{~h}$ respectively, each aliquots being replaced simultaneously by an equal volume of medium to maintain constant volume. The amount of domperidone was determined spectrophotometrically using UV spectrophotometer at $\lambda \max 287 \mathrm{~nm}$. The test was carried out in triplicate. The amount of drug released was calculated using standard calibration curve of the drug in $0.1 \mathrm{M} \mathrm{HCl}$. The drug release profiles for various MS formulations were plotted as the percent of domperidone released from the MS vs. time and further studied for the release kinetics.

\section{h) Drug Release Kinetics}

To determine the mechanism of drug release from MS, data were subjected to further analysis. The data were fitted to zero order (equation 1), first order (equation 2) and Higuchi's matrix diffusion controlled (equation 3) kinetics ${ }^{33,34}$.

$\mathrm{Q}_{\mathrm{t}}=\mathrm{Q}_{0}-\mathrm{K}_{0} \mathrm{t} \ldots \ldots \ldots \ldots \ldots \ldots \ldots \ldots \ldots \ldots \ldots \ldots \ldots$ Equation 1

$\log \mathrm{Q}_{\mathrm{t}}=\log \mathrm{Q}_{0}-\mathrm{K}_{1} \mathrm{t} / 2.303 \ldots \ldots \ldots$..... Equation 2

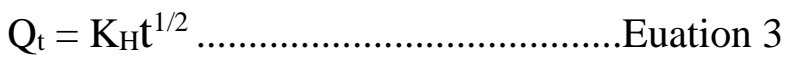


Where, $\mathrm{Q}_{\mathrm{t}}$ is the amount of drug released in time $\mathrm{t}, \mathrm{Q}_{0}$ is the initial amount of the drug in the solution, $\mathrm{K}_{0}$ is the zero order release rate constant, $\mathrm{K}_{1}$ is the first order release rate constant, $\mathrm{K}_{\mathrm{H}}$ is the Higuchi diffusion rate constant, and geometrical characteristics of the tablets.

\section{Formulation and Evaluation of ODT-SR}

The formulation of ODT-SRs involved preparation and evaluation of dry blend of MS with suitable excipients for compression followed by direct compression into tablets.

\section{Preparation and Physical Characterization of Blends Ready for Compression}

MS were dry blended in a tumbling cylindrical blender with suitable excipients like mannitol (diluent), lactose (diluent), microcrystalline cellulose (diluent) crospovidone, (super disintegrant), magnesium stearate (lubricant), sodium saccharine (sweetner) and Aerosil (glidant) to prepare seven batches (F1-F7) with various compositions (Table 2). The blends ready for compression were evaluated for various physicochemical characteristics such as angle of repose, bulk density, tapped density, percent compressibility and Hausner's ratio.

\section{Preparation and Evaluation of ODT-SR}

A single punch tablet compression machine (Cadmach Company, India), equipped with flat faced punches with a die diameter of $8 \mathrm{~mm}$ was employed to prepare tablets with an average weight of $200 \mathrm{mg}$. ODT-SRs were evaluated for the following parameters:

\section{a) Uniformity of Mass for Single-dose Preparations}

The individual and average weight of 20 tablets from each batch was determined using an electronic balance and conformity to uniformity of mass test for tablets for each batch was established $^{35}$. The average mass was expressed in $\mathrm{mg} \pm$ S.D.

\section{b) Thickness of Tablets}

Thickness of tablets was assessed using a Vernier caliper (Fisher Scientific, USA). 


\section{c) Hardness}

The Monsanto hardness tester was used to measure the crushing strength of the tablets. The average hardness (mean of three determinations) was calculated.

\section{d) Drug Content}

Domperidone content in the ODT-SR was determined. Briefly, 20 tablets were selected randomly and triturated with the help of morter and pestle. The amount equivalent to weight of one tablet was weighed and domperidone content was determined using UV-Vis Spectrophotometer at $\lambda \max$ 287 nm against blank.

\section{e) Friability}

According to European Pharmacopoeia ${ }^{35}$, sample of twenty tablets was accurately weighed and placed in the drum of tablet friability tester (Electrolab EF-1W India) revolving at $25 \mathrm{rpm}$ for 4 min. At the end of the 100 rotations, the tablets were removed, dusted and reweighed to determine the loss in the weight of the tablets.. The percentage friability was determined using the following equation:

$$
\text { Friability }(\%)=\frac{\text { Final weight-Initial weight }}{\text { Initial weight }} \times 100
$$

\section{f) Disintegration Time}

The mean disintegration time for six ODT-SRs were determined in seconds $( \pm$ S.D).

\section{g) In-vitro Drug Release}

In-vitro drug release from ODT-SR was studied using USP type II dissolution test apparatus (Electrolab EDT-08Lx) in $900 \mathrm{ml}$ of $0.1 \mathrm{M} \mathrm{HCl}$ maintained at $37 \pm 0.5{ }^{0} \mathrm{C}$ with paddle speed of rotation of $100 \mathrm{rpm}$. Domperidone content was analyzed at $\lambda \max$ of $287 \mathrm{~nm}$ using $\mathrm{UV}-\mathrm{Vis}$ spectrophotometer. 


\section{h) Stability Study}

The stability of the developed ODT-SR was conducted for 12 weeks. Optimized formulation (F4) was selected for the stability study. Briefly, samples were stored in the sealed aluminium pouch at $25^{\circ} \mathrm{C} / 60 \% \mathrm{RH}$ and at $40^{\circ} \mathrm{C} / 75 \% \mathrm{RH}$. Samples were analyzed for appearance, domperidone content and drug release profile during the stability study duration of 12 weeks.

\section{i) InVivo Pharmacokinetic Study}

Pharmacokinetic study of optimized ODT-SR (F4) was carried out in Wistar rats after oral administration and compared with a conventional marketed domperidone tablet (OC2). The protocol of the study was approved by the Institutional Animal Ethics Committee of C.U.Shah College of Pharmacy, SNDT Women's University, Mumbai.

\section{i) Animal Specification}

Wistar rats weighing about 180-220 g were used for the study. Animals were fed with a standard pelletised diet and were given free access to water.

\section{ii) Drug Administration and Collection of Plasma}

The ODT-SR of domperidone was administered orally at a single dose of $1.64 \mathrm{mg} / 200 \mathrm{~g}$ body weight after dispersing it in normal saline ${ }^{36}$. Necessary corrections were made and the animal dosage was determined from the human dose using the conversion factor ${ }^{37}$. An identical dose was given for the marketed domperidone tablet. The marketed domperidone tablet was grinded and dispersed in $1.5 \mathrm{ml}$ of $0.5 \%(\mathrm{w} / \mathrm{v})$ carboxymethylcellulose-sodium (CMC-Na) solution and tablet suspension was administered to rat by oral gavage ${ }^{38}$. After administration of the formulations, blood was withdrawn using the sparse withdrawal technique at suitable intervals of $0.5,1,2,4,6$, $8,10,14,15$ and $24 \mathrm{~h}$ from the retro-orbital plexus of the rat eye. For withdrawal of blood from 
retro-orbital plexus, the animals were exposed to chloroform vapors and made unconscious temporarily and the blood was withdrawn using fine capillary and collected in a test tube containing $0.3 \%$ sodium citrate solution as an anticoagulant. Blood was centrifuged for 10 minutes at $3000 \mathrm{rpm}$. The supernatant layer of plasma was separated by micropipette and was stored at $20^{\circ} \mathrm{C}$ until further analysis.

\section{iii) Extraction of Drug from Plasma}

To $500 \mu \mathrm{l}$ of plasma, $1.5 \mathrm{ml}$ of acetonitrile was added and vortexed for 3 minutes, followed by centrifugation at $3000 \mathrm{rpm}$. After centrifugation, supernatant layer of acetonitrile was carefully separated and analyzed using a validated HPLC method.

\section{iv) Chromatographic Conditions}

Analysis of domperidone in plasma samples was carried out by reverse phase HPLC (Aigilent Technologies 1200 series $)$. The chromatography was carried out using C-18 column $(25 \mathrm{~cm} \times 4.5$ $\mathrm{mm}, 0.5 \mu \mathrm{m})$ at $287 \mathrm{~nm}$ wavelength $(\lambda)$ with a mobile phase of buffer $(\mathrm{pH} 7.4)$ :acetonitrile $(2: 1)$ at flow rate of $1 \mathrm{ml} / \mathrm{min}$. The injection volume was kept constant at $10 \mu \mathrm{l}$ and run time was maintained for 20 minutes.

\section{v) Pharmacokinetic Analysis}

Standard methods ${ }^{39}$ were used to calculate the pharmacokinetic parameters such as area under the drug-concentration time-curve (AUC), half- life $(t 1 / 2)$ and mean residence time (MRT) using noncompartmental analysis. The maximum plasma concentration of drug $(C \max )$ and time to reach $C \max (T \max )$ were directly computed from the plasma concentration $v s$. time plot. 


\section{f) Statistical Analysis}

Statistical comparisons of the experimental results were performed by one-way analysis of variance (ANOVA) at an alpha level of 0.05 . The difference in results between the 2 groups was compared by Tukey-Kramer multiple comparison test at the significance levels of $P<0.05$.

\section{Results and Discussion}

\section{Domperidone Loaded Microspheres}

\section{a) Preparation of Microspheres}

Ethyl cellulose was used as the polymer for the preparation of sustained release MS. Ethyl cellulose solution at a level of $0.5 \% \mathrm{w} / \mathrm{v}$ or less was not viscous enough to form and/or sustain the formed micro droplets, which is essential for the formation of MS. On the other hand, the polymer solution was found to be too viscous to pass through syringe when used at $3 \% \mathrm{w} / \mathrm{v}$ concentration level and did not yield droplets of desirable size for preparation of MS, but rather resulted in the formation of large aggregates. Therefore, three polymer concentrations, greater than $0.5 \% \mathrm{w} / \mathrm{v}$ and less than $3 \% \mathrm{w} / \mathrm{v}$ viz. $1.5,2$ and $2.5 \% \mathrm{w} / \mathrm{v}$ were investigated for the optimization of preparation of MS along with the second input variable, drug concentration using $3^{2}$ factorial designs and their effect on the mean particle size, percent yield, and percent drug entrapment was observed.

It was observed that with the increase in polymer concentration from lower level $\left(\mathrm{X}_{1},-1\right)$ to higher level $\left(\mathrm{X}_{1},+1\right)$, at all three drug levels $\left(\mathrm{X}_{2},-1,0\right.$ and +1$)$ resulted in the increase in the mean particle size of MS from 58 to $196 \mu \mathrm{m}$. This increase in particle size may be because of the increase in viscosity of the droplets due to the increased polymer concentration. The increase in viscosity was high enough to result in difficulty in dispersion and subdivision of the droplets. Similar effects have been reported for ethylcellulose MS prepared by water-in-oil-in-oil double emulsion solvent 
diffusion technique ${ }^{40}$. Increase in drug concentration from lower level $\left(\mathrm{X}_{2},-1\right)$ to higher level $\left(\mathrm{X}_{2}\right.$, +1) also resulted in increase in mean particle size of the MS. Increase in mean particle size with the increase in the drug concentration may also be because of the increase in viscosity of the droplets present in the internal phase caused by the increased drug concentration.

Polymer concentration at medium level $\left(\mathrm{X}_{1}, 0\right)$ and domperidone at the highest level $\left(\mathrm{X}_{2},+1\right)$ yielded MS with the highest drug entrapment (74\%) as well as highest percent yield (86\%). When $\mathrm{X}_{1}$ was set at the medium level (0) and $\mathrm{X}_{2}$ was set either at the lower (-1) or at the medium level (0), less than $74 \%$ of the drug was found to load in the MS and also resulted in lower percent yield.

The effects of the input variables on the \% drug entrapment, particle size and percent yield of domperidone ethylcellulose MS were statistically analysed using analysis of variance, ANOVA. The data obtained was then used to generate predictor equations for domperidone concentration and polymer concentration. The results of ANOVA are given in Table 1a.

Percentage drug entrapment of the MS showed a $\mathrm{R}^{2}$ value of 0.999 , indicating a good fit. Also, percent yield and particle size of the MS showed a $\mathrm{R}^{2}$ value of 0.9997 and 0.9961 respectively indicating a good fit.

Regression of the data resulted in the equations:

$\mathrm{Y}_{1}=48.67-23.83 \mathrm{X}_{1}-5.33 \mathrm{X}_{2}-13.25 \mathrm{X}_{1} \mathrm{X}_{2}-28.50 \mathrm{X}_{1}^{2}+8.00 \mathrm{X}_{2}^{2}$

$\mathrm{Y}_{2}=89-2.17 \mathrm{X}_{1}-21.67 \mathrm{X}_{2}-56.0 \mathrm{X}_{1} \mathrm{X}_{2}-64.5 \mathrm{X}_{1}^{2}+35 \mathrm{X}_{2}^{2}$

$\mathrm{Y}_{3}=60-22.5 \mathrm{X}_{1}-14.5 \mathrm{X}_{2}-29.5 \mathrm{X}_{1} \mathrm{X}_{2}-18.00 \mathrm{X}_{1}^{2}+13.5 \mathrm{X}_{2}^{2}$

Where dependent variables $Y_{1}$ is the drug entrapment, $Y_{2}$ is the particle size and $Y_{3}$ is the percent yield of the domperidone loaded ethyl cellulose MS. Whereas $X_{1}$ and $X_{2}$ are the independent 
variables corresponding to amount of ethyl cellulose $(\% \mathrm{w} / \mathrm{v})$ and amount of domperidone $(\% \mathrm{w} / \mathrm{v})$ in MS respectively.

\section{b) Characterization of MS}

\section{i)Appearance and Particle size}

The MS were white in color, spherical in shape and free flowing with rigid morphology. The MS were in the size range of $45-189 \mu \mathrm{m}$ with mean particle size of $151 \mu \mathrm{m}$ (Figure 2a). The particle size of MS was well within $\leq 200 \mu \mathrm{m}$ limit and would thus avoid any gritty feeling in the mouth

after disintegration. It is well known that particle size above $200 \mu \mathrm{m}$ causes rough mouth feel though threshold particle size within ODT required for feeling roughness has been determined to be $>200 \mu \mathrm{m}$ because of the palatability of the exicipients like mannitol used in $\mathrm{ODT}^{25,41}$.

\section{ii) Calibration Curve of Domperidone}

Calibration curve of domperidone was prepared in $0.1 \mathrm{M} \mathrm{HCl}$. Equation for calibration curve obtained was $y=0.0375 x-0.051$; and a $R^{2}$ value of 0.996 estabilished the linearity in the concentration range of $2-20 \mu \mathrm{g} / \mathrm{ml}$.

\section{iii) Scanning Electron Microscopy}

The SEM studies revealed domperidone loaded MS were spherical in shape. However the surface of MS was rough with a porous texture (Figure 2b). This is in confirmation with earlier reports on MS prepared with ethyl cellulose polymer ${ }^{42,43}$.

\section{iv) Differential Scanning Calorimetry (DSC)}

The drug could be either dispersed in crystalline or amorphous form or dissolved in the polymeric matrix during the process of micro encapsulation. Any abrupt or drastic change in the thermal 
behavior of either the drug or polymer may indicate a possible drug-polymer interaction. DSC of domperidone MS (Figure 3) displayed characteristic, well recognizable endothermic peak of domperidone at the $254^{\circ} \mathrm{C}$, temperature corresponding to the melting point of the pure drug indicating that the drug is compatible with the polymer and no significant transformation of the drug has occurred after processing ${ }^{44}$. There was no change in the melting endotherm of the polymer confirming absence of any drug polymer interaction.

\section{v) In-Vitro Drug Release}

Several techniques have been utilized to improve the dissolution of active pharmaceutical ingredient ${ }^{45}$. It has been reported ${ }^{44}$ that the dissolution profile of domperidone pure drug in a acidic medium of $\mathrm{pH} 1.2$ buffer showed drug to dissolve to the extent of $91 \%$ in $2 \mathrm{~h}$, however, in an alkaline $\mathrm{pH}$ the dissolution of the drug was much slower, with as much as only $16 \%$ dissolved in $15 \mathrm{~min}$. in buffer of $\mathrm{pH}$ 6.8. As maintenance of sink conditions is an important requirement of dissolution media and drug release from the microspheres is the desirable rate limiting factor, dissolution studies were performed in $\mathrm{pH} 1.2$ buffer $^{46}$.

In-vitro release of domperidone from ethyl cellulose MS exhibited initial burst release with 23\% of drug being released in $1 \mathrm{~h}$. This is a common observation in the MS formulations due to the presence of drug particles on the surface of the MS. The burst effect seen during the in-vitro release from the MS was lower in case of MS prepared from higher concentration of the polymer ${ }^{47,48,}$. After the burst release, all the domperidone MS formulations showed sustained release of the drug up to $9 \mathrm{~h}$. The best fit with the highest correlation coefficient was shown in Higuchi equation followed by first-order and then zero-order equation (Table 1b). High correlation observed in the Higuchi plot rather than first-order and zero-order models indicated matrix controlled drug release 
kinetics. Previously reported Zidovudine MS prepared using ethyl cellulose has shown similar release profile $\mathrm{p}^{42,43}$.

\section{Orodispersible Sustained Release Tablet}

\section{a) Physical Properties of the Tablet Blend}

Table 3 reports the evaluation of physical properties like bulk density, tap density, percent compressibility and Hausner ratio of blends ready for compression for all ODT-SR batches. According to literature ${ }^{49}$ powders with a percent compressibility between 5 and $18 \%$ are suitable for producing tablets and those with a Hausner ratio below 1.25 have good flowability. ODT-SR blends of all batches demonstrated a percent compressibility between 8.37 and 15.04 and a Hausner ratio below 1.25. Percent compressibility and Hausner ratio of ODT-SR blends suggests good compressibility for all formulations, except F5 and F7. The ODT-SR blend of all the batches also showed good flowability (angle of repose $<30^{\circ}$ ), except batch F1 with an angle of $42.16^{\circ}$. The poor flowability of F1 may be attributed to the presence of only microcrystalline cellulose having filamentous particles as a diluent ${ }^{50}$.

\section{b) Evaluation of Orodispersible Sustained Release Tablet}

The thickness of all the tablets was found in range of 2.37 to $2.41 \mathrm{~mm}$ and was within the prescribed limits $( \pm 5 \%)^{51}$. All tablets were acceptable in terms of uniformity of mass ${ }^{35}$. Friability of all batches was less than $1 \%$ and hardness was found to be within the limits specified (35-40 N) for fast disintegrating tablets (Table 4).

\section{i) Disintegration Time}

As ODT-SR was formulated as compressed tablet ODT, crospovidone was used as superdisintegrant to provide quick disintegration of the tablet ${ }^{52}$. The time for disintegration for ODT is usually considered less than a minute ${ }^{53}$. However there is lack of globally harmonized 
nomenclature and disintegration criteria for ODTs. For example the European Pharmacopoeia ${ }^{35}$ defines orodispersible dosage forms as having disintegration time of less than 3 min but US FDA guidelines for ODTs state that ODTs should have in-vitro disintegration time of 30 seconds or less $^{54,55}$. The ODT-SR formulations (FI-F7) disintergrated in less than a minute meeting the requirements of the European Pharmacopoeia, batch F4 with disintegration time of 21 seconds also met the more rigrous guidelines of US FDA (Table 4) and was selected for further studies. Spray-dried mannitol and microcrystalline cellulose in the ratio 1:1 in batch F4 contributed to its fast disintegration. The batch F6 containing a higher amount of spray-dried mannitol showed increased disintegration time. Increase in disintegration time may be due to the increase in the polyol quantity in the tablet formulations. As polyols are readily soluble in water, there exists a competition between spray-dried mannitol and Crospovidone for water penetrating into the tablet, consequently leading to poor swelling of Crospovidone with subsequent delay in disintegration. Disintegration time of tablets of batch F5 containing microcrystalline cellulose and spray-dried lactose in a 1:1 ratio was also slightly higher than F4, probably because of the formation of a sticky layer due to the dissolution of the lactose and subsequent hindrance in the further ingress of water into the tablet in accordance with the study of Khan et $\mathrm{al}^{56}$.

\section{ii) In-vitro Drug Release}

When the selected ODT-SR (F4) was placed in in-vitro release medium it disintegrated rapidly releasing the intact MS. The drug release from these MS was similar to that obtained prior to compression and confirmed the maintenance of integrity of the MS on compression. As observed in the dissolution profile of MS, there was burst release of $23 \%$ in $1 \mathrm{~h}, 50 \%$ of the drug released in $2.26 \mathrm{~h}$ and $90 \%$ of drug was released in $7.53 \mathrm{~h}$. The drug release typically followed Higuchi square root kinetics with sustained drug release up to $9 \mathrm{~h}$. This is totally in contrast with 
conventional orodispersible tablets (OC1) of domperidone which released $100 \%$ of the drug in 10 min and while the conventional domperidone tablets (OC2) released the drug in $2 \mathrm{~h}$ (Figure 4).

\section{iii) Stability}

Stability studies of ODT-SR (F4) stored in an aluminium package under normal temperature and in a controlled stability chamber at $40{ }^{\circ} \mathrm{C}$ and $75 \% \mathrm{RH}$ for 12 weeks, showed no significant changes in the domperidone content, drug release profile and color of the tablets. The content of domperidone was stable ranging from $97.66 \%$ to $98.78 \%$ during 12 weeks after storage at $25^{\circ} \mathrm{C}$ and $60 \% \mathrm{RH}$, or from $98.24 \%$ to $98.88 \%$ during the same period after storage at $40^{\circ} \mathrm{C}$ and $75 \%$ RH. Drug release profile of $\mathrm{F} 4$ in terms of $\mathrm{t}_{10 \%}, \mathrm{t}_{50 \%}$ and $\mathrm{t}_{90 \%}$ was found in the range of $0.29 \mathrm{~h}$ to $0.34 \mathrm{~h}, 2.24 \mathrm{~h}$ to $2.34 \mathrm{~h}$ and $7.53 \mathrm{~h}$ to $7.65 \mathrm{~h}$ respectively, during 12 weeks after storage at $25^{\circ} \mathrm{C}$ and $60 \% \mathrm{RH}$ and $0.34 \mathrm{~h}$ to $0.39 \mathrm{~h}, 2.22 \mathrm{~h}$ to $2.68 \mathrm{~h}$ and $7.65 \mathrm{~h}$ to $7.81 \mathrm{~h}$ respectively, for 12 weeks after storage at $40^{\circ} \mathrm{C}$ and $75 \% \mathrm{RH}$.

\section{iv) In-vivo Pharmacokinetic Studies of Domperidone}

Domperidone after oral administration in Wistar rat was absorbed rapidly from the conventional formulation giving a mean peak plasma concentration of $23.53 \mu \mathrm{g} / \mathrm{ml}$ within $4 \mathrm{~h}$ after treatment. Domperidone is known to undergo rapid and complete absorption from gut ${ }^{57,58}$. The drug plasma concentration declined rapidly thereafter with no drug being detected beyond $8 \mathrm{~h}$. Domperidone undergoes rapid first pass metabolism though renal clearance is low ${ }^{59}$. Conventional formulation showed much shorter $t_{1 / 2}$ as compared to that reported for humans. This is consistent with an earlier study showing $\mathrm{t}_{1 / 2}$ of $1.40 \pm 0.02 \mathrm{~h}$ for domperidone in rat ${ }^{60}$.

The ODT-SR (F4) of domperidone gave a mean peak plasma concentration of $20.4266 \mu \mathrm{g} / \mathrm{ml} 10$ h post administration (Figure 5). The ODT-SR maintained drug concentration in plasma up to 24 $\mathrm{h}$ as compared to the conventional formulation, where the drug levels could no longer be detected 
after $8 \mathrm{~h}$. It was also observed that MRT of the domperidone ODT-SR (11.16 h) was 2.9 times higher than that of the conventional marketed formulation $(3.86 \mathrm{~h})$ indicating prolonged residence in the body. Thus, significant sustained drug plasma levels were observed with ODT-SR indicating rate controlled release of domperidone from the MS after oral administration. when compared to the marketed formulation (Table 5).

The mean AUC of the ODT-SR was $415.3 \mu \mathrm{g} . \mathrm{h} / \mathrm{ml}$, which was almost 3 times greater than AUC obtained with conventional marketed domperidone tablet indicating higher bioavailability of the ODT-SR. Statistical analysis by ANOVA revealed significant difference between two groups in the values of $\mathrm{C}_{\max }, \mathrm{T}_{\max }, \mathrm{AUC}$, and MRT as revealed by the $\mathrm{F}$ value at $5 \mathrm{DF}$ and $\mathrm{P}<0.05$.

\section{Conclusion}

The present platform technology combines the convenience of fast dissolving orodispersible dosage form and performance of controlled release delivery system. Not only would it address some of the problems encountered in administration of drugs to the pediatric and elderly patient, which constitutes a large proportion of the world's population but also has added therapeutic advantages of less frequent administration, patient compliance, predictable and reproducible drug release, steady drug plasma levels with better treatment efficiency.

The ODT-SR of domperidone disperses readily within $21 \mathrm{sec}$ without exceeding the disintegration time limitation specified in the US FDA guidelines for ODT ( $<30 \mathrm{sec}$ ) into MS of size range of 45-189 $\mu \mathrm{m}$, which released the drug in sustained manner over the period of $9 \mathrm{~h}$. The in-vivo pharmacokinetic study in Wistar rats revealed that the ODT-SR maintained drug concentration in plasma up to $24 \mathrm{~h}$ with three times higher bioavailability. Statistical analysis by ANOVA revealed significant difference between marketed conventional tablet of domperidone and ODT-SR. Thus this product has convenience of orodispersible dosage form and a benefits of sustained release 
system combined in one. The developed technology is simple and can be easily scaled up and thus, holds enormous potential for commercial exploitation.

\section{Acknowledgements}

The authors are thankful to Alkem Laboratories Pvt. Ltd., Mumbai, for providing the gift sample of Domperidone.

\section{Declaration of Interest}

The authors reprt no declaration of interest.

\section{References}

1. Slavkova M, Breitkreutz J. Orodispersible drug formulations for children and elderly. Eur J Pharm Sci 2015; 75: 2-9.

2. Stegemann S, Gosch M., Breitkreutz, J. Swallowing dysfunction and dysphagia is n unrecognzed challenge for oral drug therapy. Int J Pharm 2012; 430: $197-206$.

3. Dobetti L. Fast-melting tablets: developments and technologies. Pharm Tech $2000 ; 12: 32-42$.

4. Liew KB, Tan YTF, Peh KK. Taste-masked and affordable donepezil hydrochloride orally disintegrating tablet as promising solution for non-compliance in Alzheimer's disease patients. Drug Dev Ind Pharm 2015; 41(4): 583-93

5. Guhmann M, Preis M, Gerber F, Pöllinger N, Breitkreutz J, Weitschies W. Design, development and in-vitro evaluation of diclofenac taste-masked orodispersible tablet formulations. Drug Dev Ind Pharm 2015; 41(4): 540-51.

6. Manyikana M, Choonara YE, Tomar LK, Tyagi C, Kumar P, de Toit LC, and Pillay V. A review of formulation techniques that impact the disintegration and mechanical 
properties of orodispersible drug delivery technologies, Pharm Dev Technol 2015; 1-13.

7. Gugulothu D1, Desai P, Pandharipande P, Patravale V. Freeze drying: exploring potential in development of orodispersible tablets of sumatriptan succinate. Drug Dev Ind Pharm 2015; 41(3): 398-405.

8. Spierings EL, Rapoport AM, Dodick DW. Charlesworth B. Acute treatment of migraine with zolmitriptan $5 \mathrm{mg}$ orally disintegrating tablet. CNS Drugs 2004;18(15):1133-34

9. Tábi T, Szökő E, Vécsei L, Magyar K. The pharmacokinetic evaluation of selegiline ODT for the treatment of Parkinson's disease. Expert Opin Drug Metab Toxicol 2013; 9(5):629-36.

10. Roger A, Fortea J, Mora S, Artés M. Ebastine fast-dissolving tablets versus regular tablets: acceptability and preference in patients with allergic rhinitis. Expert Rev Clin Pharmacol 2008; 1:381-389.

11. Bitter I, Treuer T, Dilbaz N, Oyffe I, Ciorabai EM, Gonzalez SL, Ruschel S, Salburg J, Dyachkova Y. Patients' preference for olanzapine orodispersible tablet compared with conventional oral tablet in a multinational, randomized, crossover study. The World J Biol Psychiatry 2010;11: 894-903.

12. Dowson AJ, Almqvist P. Part III: the convenience of, and patient preference for, zolmitriptan orally disintegrating tablet. Curr Med Res Opin 2005;21 Suppl 3:S13-7.

13. Efentakis M, Naseef H, Vlachou M. Two- and three-layer tablet drug delivery systems for oral sustained release of soluble and poorly soluble drugs. Drug Dev Ind Pharm 2010; 36(8):903-16.

14. Huang YT1, Tsai TR, Cheng CJ, Cham TM, Lai TF, Chuo WH. Formulation design of an HPMC-based sustained release tablet for pyridostigmine bromide as a highly hygroscopic 
model drug and its in vivo/in vitro dissolution properties. Drug Dev Ind Pharm 2007; 33(11):1183-91.

15. Afrasiabi GH, Faghihnia TM, Sadeghi F Surelease as granulating liquid in preparation of sustained release matrices of ethylcellulose and theophylline. Drug Dev Ind Pharm 2014; 16

16. Elwerfalli AM, Ghanchi Z, Rashid F, Alany R, ElShaer A. New generation of orally disintegrating tablets for sustained drug release: A propitious outlook. Curr Drug Deliv 2015 Mar 10.

17. British Pharmacopoeia The Stationery Office on behalf of the Medicines and Healthcare products Regulatory Agency (MHRA). 2007; Volume 1, Monographs - Medicinal and Pharmaceutical Substances: Domperidone.

18. U.S. National Library of Medicine: Drug Information Portal - Domperidone [online] June 2001 Available at: (http://druginfo.nlm.nih.gov/drugportal/) [Accessed on 21 Nov 2014].

19. Albright LM. Use of Domperidone as a prokinetic and antiemetic, health and wellness. Intl Pharm Comp 2005; 9:120-125.

20. Charles M, Harnett M, Yen M. Domperidone, a new dopamine antagonist, Canadian Medical Association Journal 1986; 135(5): 457-61.

21. Phutane P, Shidhaye S, Lotlikar V, Ghule A, Sutar S, and Kadam V. In vitro evaluation of novel sustained release microspheres of glipizide prepared by the emulsion solvent diffusion-evaporation method. J Young Pharm 2010; 2(1): 35-41.

22. Swain S, Behera UA, Beg SA, Sruti J, PatroCC, Dinda SC, M. Rao EB. Design and characterization of enteric-coated controlled release mucoadhesive microcapsules of Rabeprazole sodium. Drug Dev Ind Pharm 2013; 39 (4): 548-560. 
23. Pepic D, Nikolic M, Grujic, S Lausevic M, Djonlagic J. Release behaviour of carbamazepine-loaded poly(E-caprolactone)/poly(ethylene oxide) microspheres. J Microencapsul 2013;30( 2):151-160.

24. Martinac A, Filipovic-Grcic J, Voinovich D, Perissutti B and Franceschinis E. Development and bioadhesive properties of chitosan-ethylcellulose microspheres for nasal delivery. Int J Pharm 2005; 291: 69-77.

25. Kimura S, Uchida S, Kanada K, Namiki N. Effect of granule properties on rough mouth feel and palatability of orally disintegrating tablets. Int J Pharm 2015; 484(1-2):156-62.

26. Jeong S. Fast-melting tablets having taste-masking and sustained release properties. US Patent 2006; 20060115529.

27. Wei Q, Yang F, Luan L. Preparation and in vitro/in vivo evaluation of a ketoprofen orally disintegrating/sustained release tablet. Drug Dev Ind Pharm 2013;39(6):928-34.

28. Jin Y, Ohkuma H, Wang H, Natsume H, Sugibayashi K, Morimoto Y. Fast-disintegration oral tablets having sustained release property. YakugakuZasshi 2002;122(11):989-94.

29. Al-mahallawi AM, Khowessah OM, Shoukri RA, Novel sustained release orally disintegrating tablet containing aceclofenac lipospheres: in-vitro and in-vivo studies. Inventi Impact Pharm Tech 2012; 2012.

30. Patrick B, O'Donnell, James W, McGinity. Preparation of microspheres by the solvent evaporation technique. Adv Drug Dev Rev 1997; 28: 25-42.

31. Yağ G, Çalış S, Arıca-Yegin B. The effect of inorganic salt type and concentration on hydrophilic drug loading into microspheres using the emulsion/solvent diffusion method. Drug Dev Ind Pharm 2014; 40(3):390-7.

32. Dvořáčková K, Doležel P, Mašková E, Muselík J, Kejdušová M, Vetchý D. The effect of 
acid $\mathrm{pH}$ modifiers on the release characteristics of weakly basic drug from hydrophliliclipophilic matrices. AAPS PharmSciTech 2013;14(4):1341-48.

33. Costa P, Lobo JMS. Modeling and comparison of dissolution profiles. Eur J Pharm Sci 2001;13:123-33.

34. Higuchi T, Mechanism of Sustained-Action Medication. Theoretical analysis of rate of release of solid drugs dispersed in solid matrices. J Pharm Sci 1963; 52:1145-1149.

35. European Pharmacopoeia; $6^{\text {th }}$ edition, Council of Europe, Strasburg, 2009;2:1009.

36. X. Qi, J. Qin, N.Ma, X. Chou, Z. Wu. Solid self-microemulsifying dispersible tablets of celastrol: formulation development, charaterization and bioavailability evaluation. Int $\mathbf{J}$ Pharm 2014; 472: 40-47.

37. Reagan-Shaw S, Nihal M, Ahmad N. Dose translation from animal to human studies revisited. FASEB J 2008; 22(3):659-61.

38. Zhang J, Li C, Xu M, Wu T, Chu J, Liu S, Ju W. Oral bioavailability and gender-related pharmacokinetics of celastrol following administration of pure celastrol and its related tablets in rats. J Ethnopharmcol 2012;144(1):195-200.

39. Gibaldi M, Perrier D. Pharmacokinetics. (2nd ed.) Marcel Dekker, New York; 1982.

40. Das, M.K. and Rama Rao, K. Evaluation of zidovudine encapsulated ethylcellulose microspheres prepared by water-in-oil-in-oil (w/o/o) double emulsion solvent diffusion technique. Acta Pol Pharm 2006; 63 (2):141-148.

41. T Shimizu, M Sugaya, Y Nakano, D Izutsu, Y Mizukami, K Okochi, T Tabata, N Hamaguchi, Y Igari. Formulation study for lansoprazole fast-disintegrating tablet. III. Design of rapidly disintegrating tablets. Chem Pharm Bull 2003; 51: 1121-1127. 
42. Das M K, Rao K R. Microencapsulation of zidovudine by double emulsion solvent diffusion technique using ethyl cellulose. Ind Pharm Sci 2007; 69 (2): 244-250.

43. Kar M, Choudhury PK. Formulation and evaluation of ethyl cellulose microspheres prepared by the multiple emulsion technique. Pharmazie 2007; 62(2):122-5.

44. Nagarsenker M S, Garad S D, Ramprakash G. Design, optimization and evaluation of domperidone coevaporates. J Control Release 2000; 63: 31-39.

45. Tiong N, Elkordy AA. Effects of liquisolid formulations on dissolution of naproxen. Eur J Pharm Biopharm 2009; 73: 373-384.

46. Amidon GL, Lennernäs H, Shah VP, Crison JR. A theoretical basis for a biopharmaceutic drug classification: the correlation of in vitro drug product dissolution and in vivo bioavailability. Pharm Res 1995;12(3):413-20.

47. Dhankar V, Garg G, Dhamija K Awasthi R A. Preparation, characterization and evaluation of ranitidine hydrochloride-loaded mucoadhesive microspheres. Polim Med 2014; 44 (2):75-81.

48. Jameela SR, Misra A, Jayakrishnan A. Cross-linked chitosan microspheres as carriers for prolonged delivery of macromolecular drugs. J Biomater Sci Polym Ed 1994; 6(7):621-32.

49. Michael E. Aulton (Ed) Aulton's Pharmaceutics:The Design and manufacture of medicines, $3^{\text {rd }}$ edition, Churchill Livingstone, 2007; 177.

50. Thoorens G, Kriera F, Bruno L, Brian C, Evrarda B. Microcrystalline cellulose, a direct compression binder in a quality by design environment-A review. Int $\mathrm{J}$ Pharm 2014; 473:64-72.

51. Lachman L, Lieberman HA, Kanig JL. The theory and practice of industrial pharmacy, Varghese publishing house, Indian edition, fourth reprint, 1991; 296. 
52. Madgulkar AR, Bhalekar MR, and Padalkar RR. Formulation Design and optimization of novel taste masked mouth-dissolving tablets of tramadol having adequate mechanical strength. AAPS PharmSciTech 2009; 10(2): 574-581.

53. Kumar V, Tiwari D. Dissolution. In: Troy DB, ed. Remington The science and practice of Pharmacy. Lippincott Williams and Wilkins, 2006:684.

54. FDA, Guidance for Industry: Orally Disintegrating Tablets, Rockville, MD, Dec. 2008. www.fda.gov/OHRMS/DOCKETS/98fr/ FDA-2007-D-0365-gdl.pdf, accessed July, 2015.

55. McLaughlin R, Banbury S, and Crowley K. Orally disintegrating tablets: The effect of recent FDA guidance on ODT technologies and applications. Pharm Technol September 2009.

56. Khan S, Kataria P, Nakhat P, Yeole P. Taste masking of ondansetron hydrochloride by polymer carrier system and formulation of rapid-disintegrating tablets. AAPS PharmSciTech 2007;8(2): 46.

57. Heykants J, Hendriks R, Meuldermans W, Michiels M, Scheygrond H, and Reyntjens H. On the pharmacokinetics of domperidone in animals and man IV. The pharmacokinetics of intravenous domperidone and its bioavailability in man following intramuscular, oral and rectal administration. Eur J Drug Metab Pharmacokinet 1981; 6:61-70.

58. Meuldermans W, Hurkmans R, Swijsen E, Hendrickx J, Michiels M, Lauwers W and Heykants J. On the pharmacokinetics of domperidone in animals and man III. Comparative study on the excretion and metabolism of domperidone in rats, dogs and man. Eur J Drug Metab Pharmacokinet 1981;6:49-60. 
59. Huang YC, Colaizzi JL. Bierman RH, Woestenborghs R, Heykants, JJ. Pharmacokinetics and dose proportionality of domperidone in healthy volunteers. J Clin Pharmacol 1986; 26: $628-632$.

60. Alhumayyd MS, Bukhari I.A, Almotrefi AA. Effect of piperine, a major component of black pepper, on the pharmacokinetics of domperidone in rats. J Physiol Pharmacol 2014; 65(6):785-89.

\section{TABLE LEGENDS}

Table No. Table Legends

Table Ia $\quad 3^{2}$ Factorial design to study effect of polymer and drug concentration in MS

Table $\mathrm{Ib} \quad$ Goodness of fit to mathematical drug release models applied to drug release kinetics of MS

Table II Compositions of ODT-SR of domperidone

Table III Physical characterization of blends of ODT-SR ready for compression 
Table IV Evaluation of ODT-SR of domperidone

Table V Pharmacokinetic parameters of domperidone in rat after oral

administration of conventional marketed tablet and developed ODT-SR (F-4)

Table I (a): $3^{2}$ Factorial design to study effect of polymer and drug concentration in MS

\begin{tabular}{cccccc}
\hline Trial No. & X1 & X2 & $\begin{array}{l}\text { Mean particle } \\
\text { Size }(\mu)\end{array}$ & $\begin{array}{l}\text { Percent } \\
\text { Yield }\end{array}$ & $\begin{array}{c}\text { Percent drug } \\
\text { entrapment }\end{array}$ \\
\hline $\mathbf{1}$ & -1 & -1 & 58 & 75 & 57 \\
$\mathbf{2}$ & -1 & 0 & 65 & 79 & 68 \\
$\mathbf{3}$ & -1 & 1 & 86 & 64 & 64 \\
$\mathbf{4}$ & 0 & -1 & 113 & 79 & 67 \\
$\mathbf{5}$ & 0 & 0 & $132+$ & 74 & 62 \\
$\mathbf{6}$ & 0 & 1 & 151 & 86 & 74 \\
$\mathbf{7}$ & 1 & -1 & 196 & 83 & 46 \\
\hline $\mathbf{9}$ & 1 & 0 & --------- & Precipitation & ---- \\
\hline
\end{tabular}

Translation of coded levels in actual values

$\begin{array}{llll}\text { Coded level } & -1 & 0 & 1\end{array}$

X1: Ethyl Cellulose (\% w/v) $1.5 \quad 2 \quad 2.5$

X2: Domperidone (\%) $\quad 0.5 \quad 1 \quad 1.5$ 
Table I (b): Goodness of fit to mathematical drug release models applied to drug release kinetics of MS

\begin{tabular}{cccc}
\hline Trial No & Zero order plot & First order plot & Higuchi's plot \\
\hline 1 & 0.9117 & 0.8994 & 0.99 \\
2 & 0.9637 & 0.8047 & 0.97 \\
3 & 0.9567 & 0.8831 & 0.97 \\
4 & 0.9691 & 0.8566 & 0.97 \\
5 & 0.9656 & 0.9079 & 0.98 \\
6 & 0.9671 & 0.9104 & 0.97 \\
7 & 0.9459 & 0.7746 & 0.98 \\
\hline
\end{tabular}

Table II: Compositions of ODT-SR of domperidone

\begin{tabular}{|c|c|c|c|c|c|c|c|}
\hline $\begin{array}{l}\text { Ingredients } \\
\text { (mg/tablet) }\end{array}$ & F1 & F2 & F3 & F4 & F5 & F6 & F7 \\
\hline Domperidone MS & 49.00 & 49.00 & 49.00 & 49.00 & 49.00 & 49.00 & 49.00 \\
\hline $\begin{array}{l}\text { Microcrystalline } \\
\text { Cellulose }\end{array}$ & 86.75 & 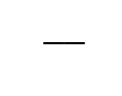 & _- & 43.37 & 43.37 & 28.91 & 28.91 \\
\hline Mannitol (Pearlitol) & --- & 86.75 & --- & 43.37 & --- & 57.83 & --- \\
\hline Lactose & --- & --- & 86.75 & --- & 43.37 & --- & 57.83 \\
\hline $\begin{array}{l}\text { Crosslinked PVP } \\
\text { (Polyplasdone XL- } \\
\text { 10) }\end{array}$ & 12.00 & 12.00 & 12.00 & 12.00 & 12.00 & 12.00 & 12.00 \\
\hline Sodium saccharine & 0.75 & 0.75 & 0.75 & 0.75 & 0.75 & 0.75 & 0.75 \\
\hline Magnesium stearate & 0.75 & 0.75 & 0.75 & 0.75 & 0.75 & 0.75 & 0.75 \\
\hline Aerosil & 0.75 & 0.75 & 0.75 & 0.75 & 0.75 & 0.75 & 0.75 \\
\hline
\end{tabular}


Table III: Physical characterization of blends of ODT-SR ready for compression

\begin{tabular}{cccccc}
\hline Batch & $\begin{array}{c}\text { Bulk } \\
\text { Density }\end{array}$ & $\begin{array}{c}\text { Tap } \\
\text { Density }\end{array}$ & $\begin{array}{c}\text { Percent } \\
\text { Compress- } \\
\text { ibility (\%) }\end{array}$ & $\begin{array}{c}\text { Angle of } \\
\text { repose }\end{array}$ & $\begin{array}{c}\text { Hausner's } \\
\text { ratio }\end{array}$ \\
\hline F1 & 0.49 & 0.58 & 14.43 & 42.16 & 1.17 \\
F2 & 0.51 & 0.57 & 11.73 & 23.00 & 1.13 \\
F3 & 0.46 & 0.50 & 8.37 & 22.11 & 1.16 \\
F4 & 0.47 & 0.54 & 11.47 & 24.02 & 1.12 \\
F5 & 0.26 & 0.35 & 25.48 & 27.75 & 1.34 \\
F6 & 0.51 & 0.60 & 15.04 & 25.42 & 1.17 \\
F7 & 0.28 & 0.38 & 26.31 & 27.93 & 1.35 \\
\hline
\end{tabular}

Table IV: Evaluation of ODT-SR of domperidone

\begin{tabular}{ccccc}
\hline Batch & Hardness & $\begin{array}{c}\text { Disintegration } \\
\text { Time(sec) }\end{array}$ & $\begin{array}{c}\text { Drug content } \\
\text { (\%) }\end{array}$ & Friability \\
\hline F1 & $35-40$ & 42 & 95.30 & 0.24 \\
F2 & $35-40$ & 39 & 97.03 & 0.21 \\
F3 & $35-40$ & 44 & 97.00 & 0.17 \\
F4 & $35-40$ & 21 & 98.95 & 0.26 \\
F5 & $35-40$ & 32 & 98.89 & 0.14 \\
F6 & $35-40$ & 55 & 98.12 & 0.23 \\
F7 & $35-40$ & 46 & 98.83 & 0.16 \\
\hline
\end{tabular}


Table V: Pharmacokinetic parameters of domperidone in rat after oral administration of conventional marketed tablet and developed ODT-SR (F-4)

\begin{tabular}{|c|c|c|c|}
\hline Parameters & 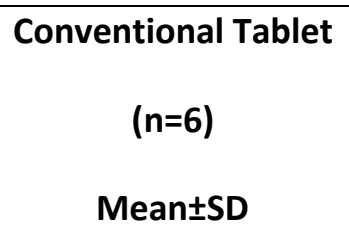 & $\begin{array}{c}\text { ODT-SR } \\
(n=6) \\
\text { Mean } \pm S D\end{array}$ & $P$ values \\
\hline $\mathrm{Cmax}(\mu \mathrm{g} / \mathrm{ml})$ & $23.53 \pm 2.45$ & $20.43 \pm 1.98$ & 0.037 \\
\hline $\operatorname{Tmax}(\mathrm{h})$ & $4 \pm 0.395$ & $10 \pm 1.095$ & 0.000 \\
\hline$t 1 / 2(h)$ & $1.07 \pm 0.056$ & $3.01 \pm 0.0215$ & 0.000 \\
\hline $\mathrm{AUC}_{0-24 \mathrm{~h}}(\mu \mathrm{g} \cdot \mathrm{h} / \mathrm{ml})$ & $136.9 \pm 13.9$ & $415.3 \pm 31.76$ & 0.000 \\
\hline $\operatorname{AUMC}_{0-24 h}\left(\mu \mathrm{g} \cdot \mathrm{h}^{2} / \mathrm{ml}\right)$ & $528.7 \pm 43.5$ & $4639 \pm 387$ & 0.000 \\
\hline MRT (h) & $3.86 \pm 0.1205$ & $11.16 \pm 0.080$ & 0.000 \\
\hline
\end{tabular}

\section{FIGURE LEGENDS}

Figure No.

Figure Legends

Fig. 1 Chemical structure of domperidone

Fig.2 (a) Particle size distribution curve and (b) SEMof domperidone microspheres 
Fig.3 Differential scanning thermograms of (a) Pure Domperidone

(b) Ethyl cellulose and (c) Domperidone microsperes.

Fig.4 Comparative dissolution profile of optimized orodispersible sustained

release tablet of domperidone (F4), marketed domperidone orodispersible (OC1) and marketed domperidone conventional tablet (OC2)

Fig.5 Plasma concentration Vs time plot of domperidone after oral

administration of marketed orodispersible tablet and developed ODT-SR in rats<smiles>O=c1[nH]c2ccccc2n1CCCN1CCC(n2c(=O)[nH]c3cc(Cl)ccc32)CC1</smiles>

Figure 1: Chemical structure of domperidone

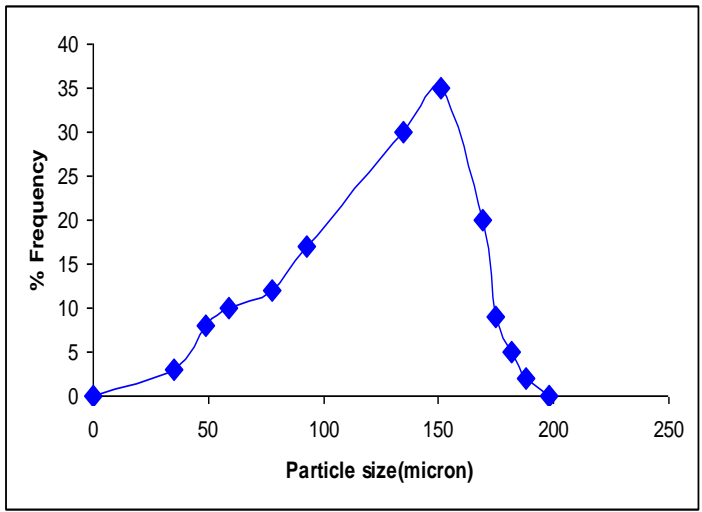

(a)

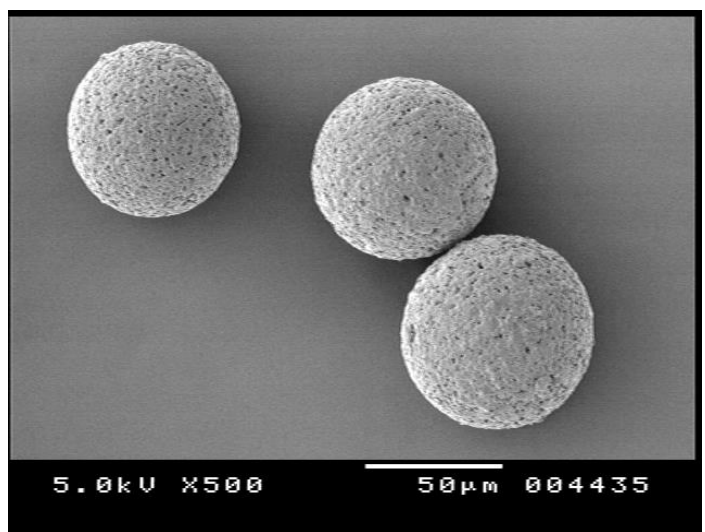

(b)

Figure 2: (a) Particle size distribution curve and (b) SEM of optimized domperidone microspheres 

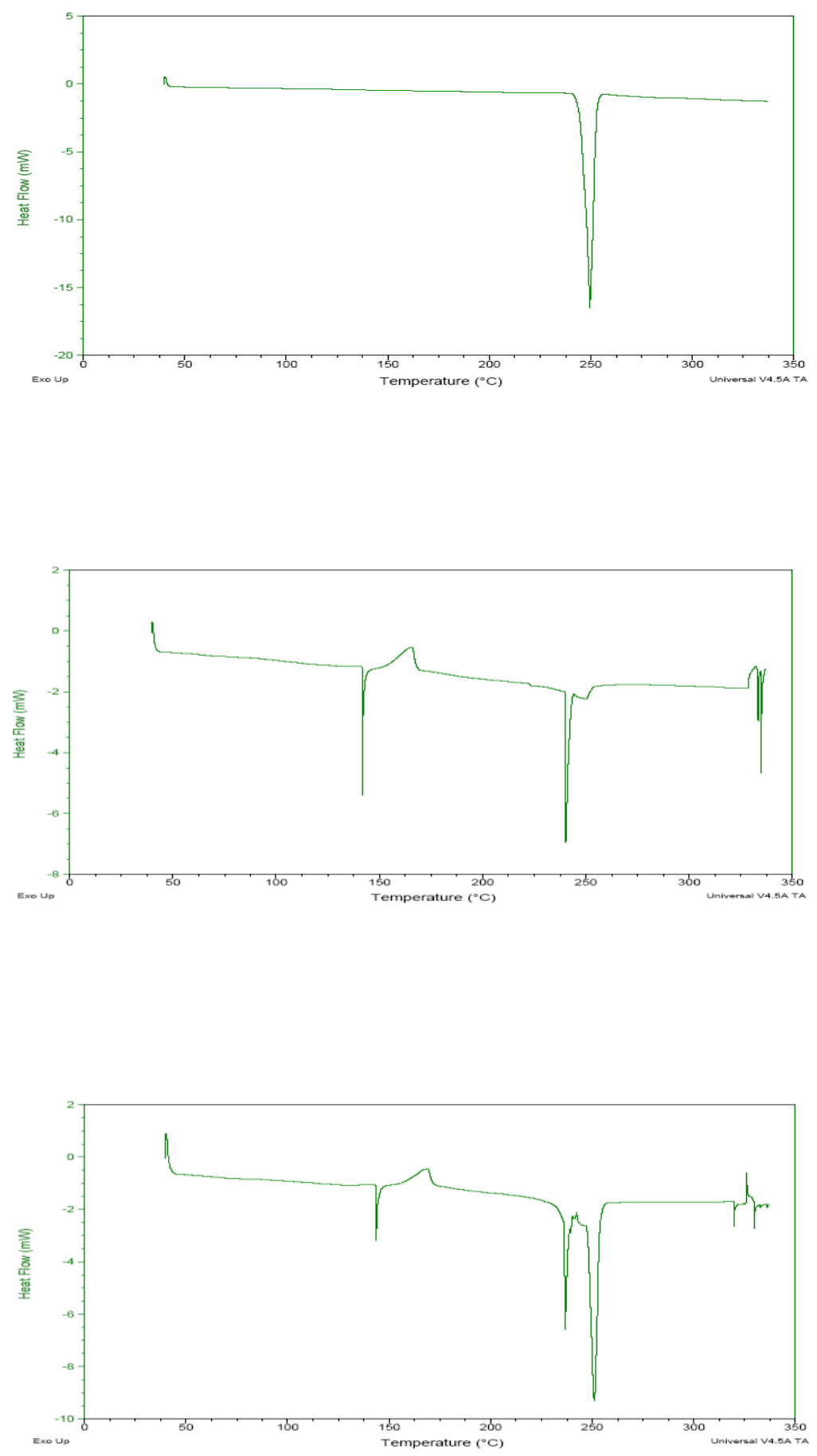

Figure 3: Differential scanning thermograms of (a) pure domperidone (b) ethyl cellulose and (c) domperidone microspheres 


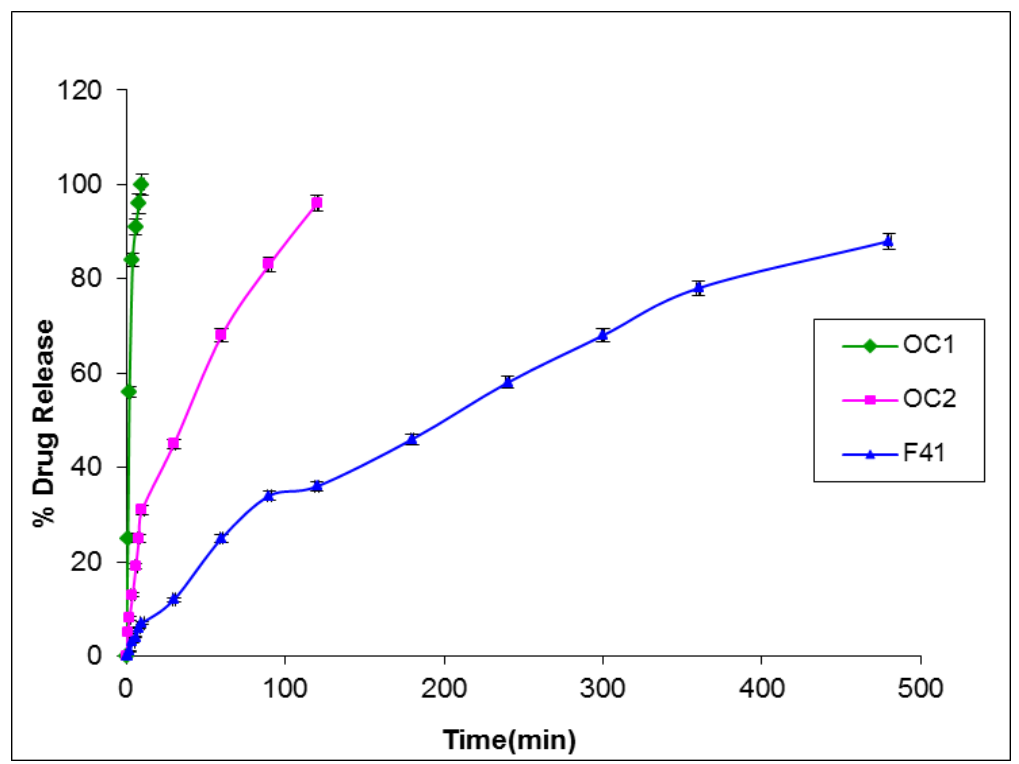

Figure 4: Comparative dissolution profile of optimized orodispersible sustained release tablet of domperidone (F4), marketed domperidone orodispersible tablet (OC1) and marketed domperidone conventional tablet (OC2)

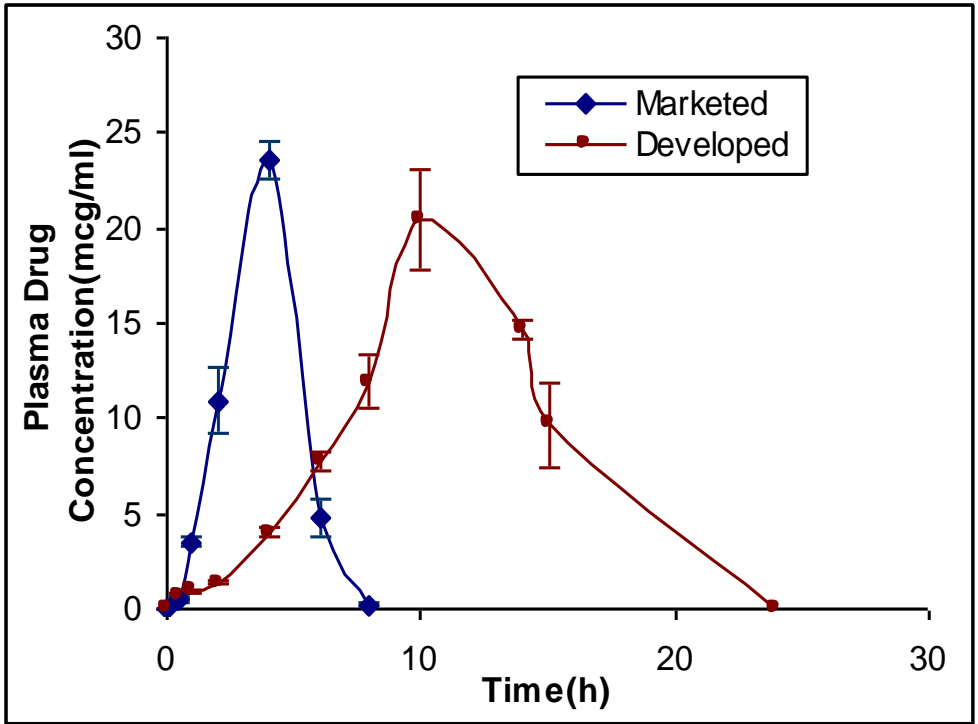

Figure 5: Plasma concentration vs. time plot of domperidone after oral administration of marketed conventional tablet and developed ODT-SR (F4) in rats 
